\title{
Mid-trimester ultrasound parameters for predicting birth weight in low risk pregnancies vs high-risk pregnancies complicated with pre-gestational diabetes mellitus
}

\author{
Anna Gasiorowska' ${ }^{1}$, Agnieszka Zawiejska² ${ }^{-}$, Piotr Dydowicz ${ }^{3}$, \\ Ewa Wender-Ozegowska² ${ }^{2}$, Grzegorz Poprawski ${ }^{4}$, Kinga Tobola-Wrobel ${ }^{5} \oplus$, \\ Katarzyna Ziolkowska ${ }^{6}$, Marek Pietryga ${ }^{3,5}$ [D \\ ${ }^{1}$ Gynaecology and Obstetrics Ward, Specialist Hospital, Zakopane, Poland \\ ${ }^{2}$ Department of Reproduction, Poznan University of Medical Sciences, Poznan, Poland \\ ${ }^{3}$ Prenatal Diagnostic Centre, Gynaecology and Obstetrics Hospital, Poznan University of Medical Sciences, Poznan, Poland \\ ${ }^{4}$ Chair and Department of Oncology, Poznan University of Medical Sciences, Poznan, Poland \\ ${ }^{5}$ Department of Obstetrics and Women's Health, Chair of Gynaecology, Obstetrics and Gynaecological Oncology, \\ Poznan University of Medical Sciences, Poznan, Poland \\ ${ }^{6}$ Chair and Department of Laboratory Diagnostics, Poznan University of Medical Sciences, Poznan, Poland
}

\begin{abstract}
Objectives: The aim of the study was to assess the utility of mid-trimester ultrasound parameters in predicting birth weight in low-risk pregnancy and high-risk pregnancy complicated with pregestational diabetes mellitus.

Material and methods: A study group comprised 97 healthy women and 160 women with pregestational diabetes (PGDM, type 1), all in singleton pregnancy. Ultrasound examination was performed between weeks 11 and 14, and in weeks 20 and 30 of gestation, based on recommendations of the Polish Society of Gynecologists and Obstetricians, Ultrasonography Division. We also checked uterine artery blood flow parameters.

Results: There is a correlation between the birth weight and ultrasound-ascertained parameters, including those characterising uterine artery blood flow and foetal biometry [abdominal circumference $(\mathrm{AC})$, femoral length (FL), biparietal dimension (BPD)].The biparietal dimension (BPD), head circumference ( $\mathrm{HC}$ ) abdominal circumference (AC) and pre-existing diabetes are the ultrasound predictors of LGA. The presence of an early-diastolic uterine artery blood flow waveform notching, as well as the uterine artery pulsatility index (UAPI), femoral length (FL) and hypertension in pregnancy are the ultrasound predictors of SGA. In the subset of women with pre-gestational diabetes (PGDM), there is a negative correlation between the birth weight and the uterine artery pulsatility index and early-diastolic uterine artery blood flow waveform notching. In women with pre-gestational diabetes mellitus (PGDM), femoral length (FL) is a significant predictor of $L G A$ and in case of SGA significant predictors are uterine artery pulsatility index, artery blood flow waveform notching and femoral length (FL).

Conclusions: Midtrimester ultrasound parameters with confirmed usefulness in the prediction of birth weight in low-risk pregnancy and high-risk pregnancy complicated with pregestational diabetes mellitus include: uterine artery PI, early-diastolic uterine artery blood flow waveform notching and foetal biometry.
\end{abstract}

Key words: birth weight; blood flow waveform notching; uterine artery pulsatility index; LGA; SGA

Ginekologia Polska 2020; 91, 4: 216-222

\section{INTRODUCTION}

The birth weight between the $10^{\text {th }}$ and $90^{\text {th }}$ percentile is crucial to ensure proper course of labour. It also reduces the risk of both early and late developmental complications. The excessive foetal weight is referred to as macrosomia and large for gestational age (LGA). The term macrosomia is related with a birth weight over $4000 \mathrm{~g}$ or $4500 \mathrm{~g}$, regardless of gestational age, with appropriate body proportions [1], whereas LGA denotes a situation where the birth weight exceeds the $90^{\text {th }}$ percentile for the relevant gestational age 
[1]. Foetal hypotrophy includes cases of small for gestational age (SGA) and intrauterine growth restriction (IUGR). The term "small for gestational age" has been coined to denote foetuses unable to reach normal body weight (defined as the $10^{\text {th }}$ percentile in a growth chart), whereas the IUGR indicates foetal growth below the genetically expected potential and applies to foetuses not reaching their potential optimum growth and weight, with growth dynamics not corresponding to the gestational age [2].

Foetal hypertrophy is associated with a number of prenatal, perinatal and postnatal complications. During the perinatal period, LGA is associated with a higher incidence of cephalopelvic disproportion, maternal pelvic floor and rectal sphincter muscle injury, shoulder dystocia and, in turn, brachial plexus palsy, hypoxia and neonatal death [3]. Long-term observation of children with macrosomia shows increased rates of overweight, obesity, diabetes, and hypertension in adult life. Children with birth weight over $4000 \mathrm{~g}$ have been found to have increased incidence of insulin resistance, risk of metabolic syndrome, abnormal fasting glycaemia and impaired glucose tolerance in childhood [4].

Foetal hypotrophy, on the other hand, is associated with an increased incidence of intrauterine death, prematurity and cerebral palsy [3].

In 1980's, the first studies evaluated the utility of uterine artery blood flow parameters in gestational trophoblastic disease and increased uterine artery resistance. Stuart Campbell published his first paper assessing blood flow in uteroplacental circulation in IUGR [5]. Fleischer et al. [6] described changes to the uterine artery blood flow waveform and an increase in the systolic-to-diastolic time index (SDI) in pregnant women with elevated blood pressure. In their paper on first trimester screening for gestational hypertension and pre-eclampsia, Gomez et al. [7] showed significantly elevated pulsatility index (PI) values in uterine arterial blood flow in patients who developed pre-eclampsia after 20 gestational weeks compared to the controls. A number of other studies followed, leading to the development of universal screening for gestational hypertension, pre-eclampsia and IUGR, i.e. all conditions associated with abnormal foetal growth leading to abnormal birth weight. This enabled us to attempt to investigate the relationship between mid-trimester uterine PI values and subsequent birth weight.

The aim of the study was to assess the utility of mid-trimester ultrasound parameters in predicting birth weight in low-risk pregnancy and high-risk pregnancy complicated with pregestational diabetes mellitus.

\section{MATERIAL AND METHODS}

The study sample was described in detail in our previous paper (Maternal factors and placental function parameters in early pregnancy as predictors of birth weight in low risk populations and among patients with pre-gestational diabetes) [8].

The women presenting for a routine antenatal appointment at 20 gestational weeks had their blood pressure measured three times using a standardized (as per FMF recommendations) manometer.

During the same appointment, an ultrasound assessment was carried out using the $3.5 \mathrm{MHz}$ abdominal probe in order to assess foetal biometry and anatomy as per the guidelines of the Ultrasound Section of Polish Society of Gynaecologists and Obstetricians as well as bilateral uterine artery blood flow as they branch out of the respective internal iliac arteries. The pulsatility index (PI) was the key assessed blood flow parameter. Each measurement was taken three times, with the highest, lowest and mean values included in statistical calculations. Furthermore, the uterine artery blood flow waveform was assessed for the presence of early-diastolic notching [9].

The statistical analysis included a logistic regression and a multiple regression models carried out using the SPSS package.

\section{RESULTS}

Study group characteristics are shown in Table 1.

There were no significant differences between healthy pregnant women and those with pregestational diabetes in terms of: height, weight, BMI, hypertension, right and left uterine artery pulsatility index and mean pulsatility index determined at about 20 gestational weeks, presence of the early diastolic right or left uterine artery blood flow waveform notching, birth weight and incidence of SGA. The mean age of women with pregestational diabetes was 29.8 years as compared to the mean age of 28.5 years in healthy pregnant women. Both systolic and diastolic blood pressure values at 20 gestational weeks were significantly higher in patients with pregestational diabetes mellitus than in healthy pregnant women $(110.1 \mathrm{mmHg}$ vs $107.5 \mathrm{mmHg}, \mathrm{p}=0.25$ and $68.7 \mathrm{mmHg}$ vs $65.5 \mathrm{mmHg}$, $p=0.23$ for systolic and diastolic BP, respectively). The mean arterial blood pressure assessed at 20 gestational weeks was significantly lower in PGDM patients than in patients in non-PGDM women (82.5 vs $86.5, \mathrm{p}=0.030$ ). The incidence of LGA in PGDM patients was significantly higher than in non-DM patients ( $21.6 \%$ vs $9 \%, \mathrm{p}=0.017$ ).

Statistical analysis demonstrated that the significant birth weight predictors were presence of the early diastolic right or left uterine artery blood flow waveform notching and the mean uterine artery pulsatility index with the inverse association between them. There was a positive correlation between the metabolic parameter, i.e. abdominal circumference $(A C)$, and the bone growth parameter, i.e. 
femoral length (FL), and the birth weight. After adjustment for pregestational weight, PAPPA level and hypertension

\begin{tabular}{|c|c|c|c|}
\hline Parameter & Non-DM & PGDM & p \\
\hline Age & $28.5 \pm 5.3$ & $29.8 \pm 4.7$ & 0.030 \\
\hline Height & $162.2 \pm 6.0$ & $166.0 \pm 6.3$ & 0.569 \\
\hline Pregestational weight & $66.2 \pm 12.4$ & $65.3 \pm 14.6$ & 0.227 \\
\hline Pregestational BMI & $24.3 \pm 4.7$ & $23.7 \pm 5.1$ & 0.161 \\
\hline $\begin{array}{l}\text { Maternal hypertensive } \\
\text { disorders [\%] }\end{array}$ & $7.2 \%$ & $11.3 \%$ & 0.386 \\
\hline $\begin{array}{l}\text { Microvascular complications } \\
\text { present (only patients with } \\
\text { PGDM) }\end{array}$ & - & $16.3 \%$ & \\
\hline $\begin{array}{l}\text { Age on DM diagnosis (only } \\
\text { patients with PGDM) }\end{array}$ & - & $18.1 \pm 8.5$ & \\
\hline $\begin{array}{l}\text { Diabetes duration (only } \\
\text { patients with PGDM) }\end{array}$ & - & $17.0 \pm 8.5$ & \\
\hline $\begin{array}{l}\mathrm{HbA}_{1 \mathrm{c}} \text { at } 20 \text { gestational weeks } \\
\text { (only patients with PGDM) }\end{array}$ & - & $5.6 \pm 0.95$ & \\
\hline $\begin{array}{l}\text { Systolic BP at } 20 \text { gestational } \\
\text { weeks }\end{array}$ & $107.5 \pm 12.5$ & $110.1 \pm 11.7$ & 0.025 \\
\hline $\begin{array}{l}\text { Diastolic BP at } 20 \text { gestational } \\
\text { weeks }\end{array}$ & $65.5 \pm 8.8$ & $68.7 \pm 10.5$ & 0.023 \\
\hline $\begin{array}{l}\text { Mean BP at } 20 \text { gestational } \\
\text { weeks }\end{array}$ & $86.5 \pm 9.7$ & $82.5 \pm 10.2$ & 0.008 \\
\hline $\begin{array}{l}\text { RUA PI at } 20 \text { gestational } \\
\text { weeks }\end{array}$ & $0.86 \pm 0.31$ & $0.89 \pm 0.29$ & 0.212 \\
\hline $\begin{array}{l}\text { LUA PI at } 20 \text { gestational } \\
\text { weeks }\end{array}$ & $0.93 \pm 0.29$ & $0.95 \pm 0.38$ & 0.553 \\
\hline $\begin{array}{l}\text { Right or left UA waveform } \\
\text { notching [\%] }\end{array}$ & 17.2 & 10.8 & 0.274 \\
\hline Mean UAPI & $0.89 \pm 0.29$ & $0.92 \pm 0.28$ & 0.246 \\
\hline Birth weight & $3314 \pm 512$ & $3388 \pm 596$ & 0.191 \\
\hline LGA \% & $9.0 \%$ & $21.6 \%$ & 0.017 \\
\hline SGA \% & $9.0 \%$ & $11.5 \%$ & 0.654 \\
\hline
\end{tabular}

$\mathrm{BMI}$ — body mass index; PGDM — pre-gestational diabetes; UAPI — uterine artery pulsatility index; LGA — large for gestational age; SGA — small for gestational age in early pregnancy, these parameters remained significant predictors of birth weight (Tab. 2).

The logistic regression demonstrated that the biparietal dimension [(BPD), $\mathrm{p}=0.049]$, head circumference [(HC), $p=0.044]$, abdominal circumference [(AC), $p=0.013]$ and pre-existent diabetes $(p=0.020)$ were significant predictors of LGA in the entire study sample. Pre-existent diabetes increased the risk of LGA three-fold compared to non-PGDM women. Positive correlation has been demonstrated between the biometric parameters, i.e. BPD, HC, AC and LGA incidence (Tab. 3). However, when the logistic regression model was adjusted for the crown-rump length (CRL), nuchal translucency (NT), P1GF level and mean pulsatility index in uterine arteries assessed during the routine appointment at 12 gestational weeks, all parameters listed in Table 3 proved non-significant.

The significant predictors of SGA in the entire study sample were the presence of an early-diastolic left uterine artery blood flow waveform notching $(p=0.018)$, mean uterine artery pulsatility index $(p=0.010)$, femoral length $(p=0.016)$ and gestational hypertension $(p=0.037)$. The highest risk of SGA was associated with a high mean uterine artery pulsatility index [(UAPI), OR = 9.97]. In the logistic regression model presented in Table 4, the presence of an early-diastolic left uterine artery blood flow waveform notching increased the risk of SGA five-fold, while hypertensive disease of pregnancy increased that risk three-fold.

In the subset of women with pregestational diabetes (PGDM), the analysis demonstrated a negative correlation between the birth weight and the following: right uterine artery pulsatility index $(p=0.010)$, an early-diastolic right uterine artery blood flow waveform notching ( $p=0.007$, an early-diastolic left uterine artery blood flow waveform notching $(p=0.010)$, higher $(p=0.008)$ and mean $(p=0.028)$ uterine artery pulsatility indices. After adjustment for maternal height, PAPPA and beta-HCG levels, these parameters still remained significant birth weight predictors (Tab. 5).

In women with pre-gestational diabetes mellitus (PGDM), femoral length (FL) was a significant predictor of

Table 2. Independent mid-trimester birth weight (a dependent variable) predictors in the entire cohort

\begin{tabular}{|c|c|c|c|c|c|c|}
\hline Parameter & & Standardised coefficient B & Non-standardised coefficient B & $95 \% \mathrm{Cl}$ for B & Adjusted $\mathbf{R}^{2}$ & p \\
\hline \multirow{2}{*}{$\begin{array}{l}\text { Right or left UA } \\
\text { waveform notching }\end{array}$} & Unadjusted & -0.215 & -313.44 & $-540.38 ;-86.50$ & 0.04 & 0.007 \\
\hline & $\mathrm{Ad}$ & -0.232 & -377.8 & $-622.4 ;-133.3$ & 0.11 & 0.003 \\
\hline \multirow{2}{*}{$\begin{array}{l}\text { Mean Pl in uterine } \\
\text { arteries }\end{array}$} & Unadjusted & -0.195 & -362.70 & $-652.6 ;-72.84$ & 0.03 & 0.015 \\
\hline & $\mathrm{Ad}$ & -0.212 & -408.7 & $-715.1 ;-102.3$ & 0.098 & 0.009 \\
\hline \multirow{2}{*}{$\begin{array}{l}\text { Abdominal } \\
\text { circumference (AC) }\end{array}$} & Unadjusted & 0.158 & 4.51 & $0.62 ; 8.41$ & 0.02 & 0.023 \\
\hline & $\mathrm{Ad}$ & 0.164 & 4.45 & $0.88 ; 8.01$ & 0.09 & 0.015 \\
\hline \multirow[t]{2}{*}{ Femoral length (FL) } & Unadjusted & 0.165 & 19.6 & $3.42 ; 35.70$ & 0.02 & 0.018 \\
\hline & $\mathrm{Ad}$ & 0.157 & 18.7 & $2.9 ; 34.6$ & 0.087 & 0.021 \\
\hline
\end{tabular}

Ad — adjusted for pregestational weight, PAPPA and hypertensive disorders of pregnancy 


\begin{tabular}{|c|c|c|c|c|c|}
\hline Independent variable in the logistic regression ENTER model & & Regression coefficient B & OR & $95 \% \mathrm{Cl}$ for OR & p \\
\hline \multirow{2}{*}{ BPD } & Unadjusted & 0.067 & 1.07 & $1.00 ; 1.14$ & 0.049 \\
\hline & $\mathrm{Ad}$ & 0.002 & 1.002 & $0.92 ; 1.09$ & 0.956 \\
\hline \multirow{2}{*}{$\mathrm{HC}$} & Unadjusted & 0.015 & 1.015 & $1.00 ; 1.03$ & 0.044 \\
\hline & $\mathrm{Ad}$ & 0.005 & 1.005 & $0.99 ; 1.02$ & 0.617 \\
\hline \multirow{2}{*}{ AC } & Unadjusted & 0.025 & 1.025 & $1.005 ; 1.045$ & 0.013 \\
\hline & $\mathrm{Ad}$ & 0.006 & 1.006 & $0.98 ; 1.03$ & 0.607 \\
\hline \multirow{2}{*}{ Pre-existent diabetes YES } & Unadjusted & 1.03 & 2.8 & $1.2 ; 6.7$ & 0.020 \\
\hline & $\mathrm{Ad}$ & 0.375 & 1.46 & $0.54 ; 3.9$ & 0.461 \\
\hline
\end{tabular}

Ad — adjusted for CRL, NT, PIGF and mean UAPI at 12 gestational weeks; BPD — biparietal dimension; HC — head circumference; AC — abdominal circumference

Table 4. Independent predictors of SGA in the entire study sample — logistic regression analysis with SGA presence/absence as a dependent variable. The data are presented as an unadjusted odds ratio

\begin{tabular}{|l|l|l|l|l|}
\hline Independent variable in the logistic regression ENTER model & Regression coefficient B & OR & $\mathbf{9 5 \%}$ Cl for OR & $\mathbf{p}$ \\
\hline Left UA waveform notching & 1.602 & 4.96 & $1.31 ; 18.74$ & 0.018 \\
\hline Mean UAPI & 2.3 & 9.97 & $1.75 ; 56.79$ & 0.010 \\
\hline FL & -0.132 & 0.88 & $0.79 ; 0.97$ & 0.016 \\
\hline Hypertensive disorders of pregnancy YES & 1.19 & 3.3 & $1.08 ; 10.02$ & 0.037 \\
\hline
\end{tabular}

UAPI - uterine artery pulsatility index; $\mathrm{FL}-$ femoral length

Table 5. Independent mid-trimester birth weight (a dependent variable) predictors in PGDM subset. The calculations were adjusted for early pregnancy factors identified as birth weight predictors in PGDM subset

\begin{tabular}{|c|c|c|c|c|c|c|}
\hline Parameter & & Standardised coefficient B & Non-standardised coefficient B & 95\% Cl for B & Adjusted $\mathbf{R}^{2}$ & $\mathbf{p}$ \\
\hline \multirow{2}{*}{$\mathrm{PI}$ in the right UA } & Unadjusted & -0.285 & -520.46 & $-912.8 ;-128.2$ & 0.07 & 0.010 \\
\hline & $\mathrm{Ad}$ & -0.263 & -537.13 & $-952.7 ;-121.6$ & 0.18 & 0.012 \\
\hline \multirow{2}{*}{$\begin{array}{l}\text { Right UA waveform } \\
\text { notching }\end{array}$} & Unadjusted & -0.296 & -605.5 & $-1043.6 ;-167.4$ & 0.09 & 0.007 \\
\hline & $\mathrm{Ad}$ & -0.307 & -702.5 & $-1155.9 ;-249.0$ & 0.21 & 0.003 \\
\hline \multirow{2}{*}{$\begin{array}{l}\text { Left UA waveform } \\
\text { notching }\end{array}$} & Unadjusted & -0.285 & -544.58 & $-954.3 ;-134.9$ & 0.07 & 0.010 \\
\hline & $\mathrm{Ad}$ & -0.318 & -677.2 & $-1104.8 ;-249.6$ & 0.21 & 0.002 \\
\hline \multirow{2}{*}{$\begin{array}{l}\text { A higher of the two } \\
\text { UAPI values }\end{array}$} & Unadjusted & -0.291 & -429.8 & $-746.3 ;-113.3$ & 0.07 & 0.008 \\
\hline & $\mathrm{Ad}$ & -0.259 & -409.1 & $-746.9 ;-71.3$ & 0.17 & 0.018 \\
\hline \multirow{2}{*}{ Mean UAPI } & Unadjusted & -0.244 & -479.3 & $-906.4 ;-52.3$ & 0.05 & 0.028 \\
\hline & $\mathrm{Ad}$ & -0.217 & -466.8 & $-928.4 ;-5.2$ & 0.20 & 0.048 \\
\hline
\end{tabular}

$\mathrm{Ad}$ - adjusted for maternal body height, PAPPA and beta-HCG; UAPI — uterine artery pulsatility index

LGA $(p=0.052)$. After adjustment for early pregnancy (12 gestational weeks) PAPPA level and mean uterine artery pulsatility index, it still remained a significant predictor of LGA $(p=0.032$ ). Albeit significant, the odds ratio of LGA in foetuses with higher FL was only slightly above 1 . The adjustment for early pregnancy (12 gestational weeks) for PAPPA level and mean uterine artery pulsatility index did not affect the odds ratio of LGA in foetuses with higher FL (OR 1.15, Tab. 6).

In women with pre-gestational diabetes, the following were significant predictors of SGA: right uterine artery pulsa- tility index $(p=0.005)$, an early-diastolic right and left uterine artery blood flow waveform notching $(p=0.008)$, higher of the two uterine artery pulsatility indices $(p=0.005)$, mean uterine artery pulsatility index $(p=0.008)$ and femoral length ( $p=0.039$ ). Regression model adjustment for P1GF level at 12 gestational weeks did not affect the significance of most analysed predictors, with FL being the only exception.

The highest risk of SGA was demonstrated in foetuses with mean uterine artery pulsatility index (unadjusted 
Table 6. Independent predictors of LGA in women with pre-gestational diabetes. Logistic regression analysis with LGA present/absent as a dependent variable. The data are presented as odds ratios - unadjusted and adjusted for known first-trimester risk factors for LGA

\begin{tabular}{|l|l|l|l|l|l|}
\hline Independent variable in the logistic regression ENTER model & & Regression coefficient B & OR & $\mathbf{9 5 \%}$ Cl for OR & $\mathbf{P}$ \\
\hline FL & Unadjusted & 0.115 & 1.12 & $0.999 ; 1.26$ & 0.052 \\
\hline & Ad & & 1.15 & $1.013 ; 1.32$ & 0.032 \\
\hline
\end{tabular}

Ad — adjusted for PAPPA and mean UAPI at 12 gestational weeks; $\mathrm{FL}$ - femoral length

Table 7. Independent predictors of SGA in women with pre-gestational diabetes. Logistic regression analysis with SGA present/absent as a dependent variable. The data are presented as odds ratios - unadjusted and adjusted for known first-trimester risk factors for SGA

\begin{tabular}{|l|l|l|l|l|l|}
\hline Independent variable in the logistic regression ENTER model & & Regression coefficient B & OR & $\mathbf{9 5 \%}$ Cl for OR & $\mathbf{P}$ \\
\hline RUA PI & Unadjusted & 4.101 & 60.4 & $3.4 ; 1086.4$ & 0.005 \\
\hline \multirow{2}{*}{ Right or left UA waveform notching } & Ad & 4.147 & 63.2 & $2.7 ; 1457.6$ & 0.010 \\
\hline \multirow{2}{*}{ A higher of the two UAPI values } & Unadjusted & 2.44 & 11.5 & $1.9 ; 69.9$ & 0.008 \\
\hline \multirow{2}{*}{ Mean UAPI } & Ad & 2.83 & 16.9 & $2.3 ; 124.8$ & 0.005 \\
\hline \multirow{2}{*}{ FL } & Unadjusted & 3.17 & 23.7 & $2.6 ; 212.1$ & 0.005 \\
\hline & Ad & 3.77 & 43.2 & $2.6 ; 714.2$ & 0.008 \\
\hline & Unadjusted & 4.36 & 78.3 & $3.1 ; 1998.6$ & 0.008 \\
\hline & Ad & 4.95 & 141.7 & $2.8 ; 723.9$ & 0.014 \\
\hline
\end{tabular}

Ad — adjusted for PIGF at 12 gestational weeks; UAPI — uterine artery pulsatility index; FL — femoral length

$\mathrm{OR}=78.3$ and adjusted $\mathrm{OR}=141.7)$. The risk of SGA in foetuses with higher right uterine artery pulsatility index was 60 -fold higher than in those with lower UAPI (unadjusted $O R=60.4$ and adjusted $O R=63.2$ ). This may indicate a lateral circulatory shift in pregnancy with higher vascular resistance in the right uterine artery than in the left one. The risk of SGA in foetuses with higher uterine artery pulsatility index was 23-fold and 43-fold higher in the unadjusted and adjusted model, respectively, than in those with lower UAPI. The presence of an early-diastolic right and left uterine artery blood flow waveform notching increased the risk of SGA 12-fold in the unadjusted model and 17-fold in the adjusted model. The femoral length (FL) did not increase the risk of SGA in both unadjusted and adjusted model but served as a significant SGA predictor in the unadjusted model (Tab. 7).

\section{DISCUSSION}

The analysis of the mid-trimester material in this study demonstrated a number of associations between ultrasound parameters and birth weight. It confirmed the previously observed correlations between the foetal biometric parameters, i.e. BPD, HC, AC, FL and birth weight, as well as the effect of first-trimester placental markers and mean uterine artery pulsatility index which we have reported previously. It showed that the uterine artery pulsatility index assessed in both first and second trimester is not only a prognostic parameter of pre-eclampsia and IUGR but also of birth weight.

Our study, although carried out in a small sample, confirmed the significance of abdominal circumference (AC) and femoral length (FL) in birth weight estimation. This finding is corroborated by the study based on ultrasound foetal biometry analysis between 22 and 43 gestational weeks in 5163 pregnancies, which proved that the Hadlock formula developed in 1985, based on the measurements of head circumference $(\mathrm{HC})$, abdominal circumference $(\mathrm{AC})$ and femoral length $(\mathrm{FL})$ provides the most accurate birth weight estimation and can be used in all foetuses, included those with suspected intrauterine growth abnormalities [10].

The paper reporting a mid-trimester screening for LGA based on maternal history and foetal biometry was published in Ultrasound in Obstetrics and Gynecology [11]. That British study was carried out in samples of 76300, 54999, 25727 and 6181 pregnant women. The procedure included antenatal ultrasound scans at 11-13, 19-24, 30-34, and 35-37 gestational weeks LGA was defined as foetal weight above the $95^{\text {th }}$ percentile. The likelihood of LGA increased with increasing maternal weight and height as well as in women with pre-existing diabetes mellitus Type I, but decreased in those with chronic hypertension, cigarette smokers and in nulliparous women. The mid-trimester screening, based on maternal history and foetal biometry, had detec- 
tion rates of $37 \%, 51 \%$ and $68 \%$, respectively, with false positive rates of $5 \%, 10 \%$ and $20 \%$, respectively.

Poon et al. evaluated the utility of complex screening based on maternal history, foetal biometry as well as biophysical and biochemical markers ascertained at 19-24 gestational weeks, in predicting SGA, excluding pre-eclampsia, and selecting the optimum timeframe for the third trimester ultrasound scan (at either 32 or 36 gestational weeks). The screening, based on maternal history, foetal biometry, uterine artery PI, P1GF and AFP levels, was carried out in 7816 pregnant women, including 389 cases of SGA. Not only was the screening crucial for SGA prediction, but it also determined the optimum timeframe for the third trimester ultrasound scan (at either 32 or 36 gestational weeks). The SGA detection rates (DR) were $100 \%, 78 \%$ and $42 \%$ for foetuses born before 32, between 32-36 and after 37 gestational weeks, respectively, with a false positive rate of $10 \%$. The third-trimester scan was needed at 32 gestational weeks in $11 \%$ and at 36 gestational weeks in $44 \%$ of the screened women, but not needed at any time in the third trimester in $57 \%$ of the screened women [12].

Lesmes et al. reported a similar mid-trimester screening protocol, yet not including biomarker levels. The screening algorithm for SGA prediction (referred to as foetal weight below the $5^{\text {th }}$ percentile) carried out at 19-24 gestational weeks was based on maternal history, MAP, foetal biometry and uterine artery pulsatility index (PI). Its utility in selecting the optimum timeframe for the third trimester ultrasound scan (at either 32 or 36 gestational weeks) was also assessed. In a group of 63,975 screened women, SGA was confirmed in 3702 (5.8\%) cases. The detection rates (DR) of their screening based on maternal history, foetal biometry and uterine artery pulsatility index were $90 \%, 68 \%$ and $44 \%$ for foetuses born before 32, between 32-36 and after 37 gestational weeks, respectively, with a false positive rate of $10 \%$.The mean arterial pressure (MAP) inclusion in the algorithm did not improve the results. Based on a hypothetical model with an assumed SGA detection rate of $80 \%$, they estimated that the third-trimester scan was needed at 32 gestational weeks in $17 \%$ and at 36 gestational weeks in $38 \%$ of the screened women, but not needed at any time in the third trimester in $62 \%$ of the screened women [13].

Familiari et al. reported a significant predictive role of uterine artery blood flow parameters in SGA screening. Their second trimester screening administered to 23,894 pregnant women at 19-24 gestational weeks was based on maternal history including age, BMI and ethnicity; foetal biometry and uterine artery pulsatility index. All abovementioned parameters correlated significantly with the risk of $S G A<5^{\text {th }}$ centile $(p<0.01)$. Uterine artery pulsatility index alone was capable of predicting $25 \%, 60 \%$ and $77 \%$ of SGA in foetuses born at $>37,<37$ and $<32$ gestational weeks, respectively, with a false positive rate of $10 \%$.Including foetal biometrics, maternal history and uterine artery pulsatility index increased SGA detection to $40 \%, 66 \%$ and $89 \%$ in foetuses born at $>37,<37$ and $<32$ gestational weeks, respectively, with a false positive rate of $10 \%$ [14].

Parry et al. described a similar study conducted in 8024 pregnant women, assessed for SGA during three consecutive antenatal visits. They measured bilateral uterine artery resistance and pulsatility indices and evaluated the presence of an early-diastolic uterine artery blood flow waveform notching in an ultrasound carried out between 16 weeks 0 days and 22 weeks 6 days gestation. SGA defined as birth weight below the 5 th percentile was confirmed in 358 cases (4.5\%). The positive predictive value for this threshold was below $15 \%$, with the area under the curve (AUC) of 0.50-0.60. The AUC additionally improved to 0.63 0.66 after including maternal age, BMI, ethnicity, smoking status, chronic hypertension, and pre-existing diabetes in the model. This test was concluded not to be clinically useful for predicting SGA [15].

\section{CONCLUSIONS}

1. There is a correlation between the birth weight and ultrasound-ascertained parameters, including those characterising uterine artery blood flow and foetal biometry [abdominal circumference (AC), femoral length $(\mathrm{FL})$, biparietal dimension (BPD)].

2. The biparietal dimension (BPD), head circumference (HC) abdominal circumference (AC) and pre-existing diabetes are the ultrasound predictors of LGA.

3. The presence of an early-diastolic uterine artery blood flow waveform notching, as well as the uterine artery pulsatility index (UAPI), femoral length (FL) and hypertension in pregnancy are the ultrasound predictors of SGA.

4. In pregnant women with pregestational diabetes (PGDM), there is a negative correlation between the birth weight and the uterine artery pulsatility index and early-diastolic uterine artery blood flow waveform notching.

5. In pregnant women with pre-gestational diabetes mellitus (PGDM), femoral length ( $F L$ ) is apredictor of LGA and uterine artery pulsatility index, artery blood flow waveform notching and femoral length (FL) are predictors in case of SGA.

\section{Author declarations}

1. Anna Gąsiorowska - designed the experiment, collected the material, drafted the manuscript and researched the literature.

2. Agnieszka Zawiejska - analysed and interpreted the results, revised article critically. 
3. Piotr Dydowicz - collected the material.

4. Ewa Wender-Ożegowska - revised the article critically.

5. Grzegorz Poprawski - collected the material.

6. Kinga Toboła-Wróbel - analysed and interpreted the data.

7. Katarzyna Ziółkowska - collected the material and carried out biochemical testing.

8. Marek Pietryga - designed the experiment, proofread, verified and finally approved the manuscript.

\section{Funding}

The research reported in the present manuscript was not financed or co-financed by any R\&D centre, association and any other institution or entity. The authors did not receive any research grant.

\section{Conflict of interest}

All authors declare that they have no conflict of interest. No financial remuneration was received relative to the technologies and concepts presented in the present manuscript.

\section{REFERENCES}

1. Rekomendacje Polskiego Towarzystwa Ginekologów i Położników dotyczące cięcia cesarskiego. Ginekologia i Perinatologia Praktyczna. 2018; 3(4): 159-174.

2. Ropacka-Lesiak M. Wewnątrzmaciczne ograniczenie wzrastania płodu. In: Bręborowicz GH. ed. Położnictwo Tom 2: Medycyna matczynopłodowa. PZWL, Warszawa 2012: 105-117.

3. Bomba-Opoń D. Nieprawidłowe wzrastanie płodu: hipotrofia i hipertrofia. In: Bręborowicz GH. ed. Położnictwo i ginekologia Tom 1: Położnictwo. PZWL, Warszawa 2016: 190-195.

4. Szejniuk W, Szymankiewicz M. Makrosomia i inne zaburzenia występujące u no-worodka matki z cukrzycą. Perinatologia, Neonatologia i Ginekologia. 2008; 1: 253-259.

5. Campbell S, Diaz-Recansens J, Grifin D, et al. New Doppler techniqe for assesing uteroplacental blood flow. Lancet. 1983: 675-677.
6. Ducey J, Schulman H, Farmakides G, et al. Uterine artery Doppler velocimetry in pregnant women with hypertension. Am J Obstet Gynecol. 1986; 154(4): 806-813, doi: 10.1016/0002-9378(86)90462-x, indexed in Pubmed: 3515946.

7. Gasiorowska A, Zawiejska A, Dydowicz $P$, et al. Maternal factors, ultrasound and placental function parameters in early pregnancy as predictors of birth weight in low-risk populations and among patients with pre-gestational diabetes. Ginekol Pol. 2019; 90(7): 388-395, doi: 10.5603/GP.2019.0067, indexed in Pubmed: 31392708.

8. Gómez O, Martínez JM, Figueras F, et al. Uterine artery Doppler at 11-14 weeks of gestation to screen for hypertensive disorders and associated complications in an unselected population. Ultrasound Obstet Gynecol. 2005; 26(5): 490-494, doi: 10.1002/uog.1976, indexed in Pubmed: 16184511.

9. Pietryga M, Gąsiorowska-Szot A, Wolski H. Badanie dopplerowskie tętnicy macicznej w medycynie perinatalnej. In: Pietryga M, Brązert J. ed. Praktyczna ultrasonografia w położnictwie i ginekologii. Exemplum, Poznań 2012: 527-553.

10. Hammami A, Mazer Zumaeta A, Syngelaki A, et al. Ultrasonographic estimation of fetal weight: development of new model and assessment of performance of previous models. Ultrasound Obstet Gynecol. 2018; 52(1): 35-43, doi: 10.1002/uog.19066, indexed in Pubmed: 29611251.

11. Frick AP, Syngelaki $A$, Zheng $M$, et al. Prediction of large-for-gestational-age neonates: screening by maternal factors and biomarkers in the three trimesters of pregnancy. Ultrasound Obstet Gynecol. 2016; 47(3): 332-339, doi: 10.1002/uog.15780, indexed in Pubmed: 26446185.

12. Poon LC, Lesmes C, Gallo DM, et al. Prediction of small-for-gestational-age neonates: screening by biophysical and biochemical markers at 19-24 weeks. Ultrasound Obstet Gynecol. 2015; 46(4): 437-445, doi: 10.1002/uog.14904, indexed in Pubmed: 25988293.

13. Lesmes $C$, Gallo DM, SaiidY, et al. Prediction of small-for-gestational-age neonates: screening by uterine artery Doppler and mean arterial pressure at 19-24 weeks. Ultrasound Obstet Gynecol. 2015; 46(3): 332-340, doi: 10.1002/uog.14855, indexed in Pubmed: 25810352.

14. Familiari A, Bhide A, Morlando M, et al. Mid-pregnancy fetal biometry, uterine artery Doppler indices and maternal demographic characteristics: role in prediction of small-for-gestational-age birth. Acta Obstet Gynecol Scand. 2016; 95(2): 238-244, doi: 10.1111/aogs.12804, indexed in Pubmed: 26472057.

15. Parry S, Sciscione A, Haas DM, et al. Nulliparous Pregnancy Outcomes Study: Monitoring Mothers-to-be. Role of early second-trimester uterine artery Doppler screening to predict small-for-gestational-age babies in nulliparous women. Am J Obstet Gynecol. 2017; 217(5): 594.e1-594. e10, doi: 10.1016/j.ajog.2017.06.013, indexed in Pubmed: 28712949. 